\title{
POWER MODULE TEMPERATURE IN SIMULATION OF ROBOTIC MANUFACTURING APPLICATION
}

\author{
O. Bormanis*, L. Ribickis \\ Institute of Industrial Electronics and Electrical Engineering \\ Riga Technical University, \\ 12-k1 Azenes Str., Riga, LV-1048, LATVIA \\ *e-mail: oskars.bormanis@gmail.com
}

The paper presents a lifetime consumption estimation model of 6 degrees of freedom industrial robot arm. The primary goal of the research is to provide estimated lifetime data of semiconductor power modules of robot axis power supply circuit, providing new opportunities for cost-saving, predictive maintenance, with highly customized input for different manufacturing applications. Evaluation of thermal stress and estimation of isolated gate bipolar transistor current are completed, based on MATLAB model translating KUKA robot program code to electrical energy consumption, which is a novel approach. Energy losses are considered in the model to provide accuracy of the inverter load current. The simulation results prove that lifetime consumption depends on a robot application type, for more agile movement programs with large power amplitudes, such as handling, the degradation in power modules is significant compared to slower applications, such as gluing or welding. Various options for future development are suggested and considered in the paper.

Keywords: Industrial application, lifetime, mission profile, reliability robotics.

\section{INTRODUCTION}

Selecting operating parameters of electric components is critical for electrical equipment. During the design phase, it is decided what derating method to apply for the required material types. Maximal values are selected to perform safely above the expected operational field life stress, pro- viding a reliability improvement for mission-critical applications, either in a harsh environment, difficult to access or with high downtime costs.

Due to high cost, there is a requirement for semiconductor power modules to decrease absolute maximum values and to 
select the material which just barely exceeds the required parameters. As a compromise between cost and performance is required, knowledge and understanding of mission profile are of major importance.

As manufacturing site development is becoming increasingly virtual, and with the introduction of virtual commissioning software, the mission profile is not just an assumption. Process flow and trajectories are set up in a virtual environment during the design phase before deployment with programs as Delmia Robotics (Dassault Systemes) [1], RobotStudio (ABB) [2], Kuka.sim (KUKA AG) [3]. Output code is ready for upload on hardware on-site, as long as the code generation is completed, including the vendor-specific realistic controller simulation module. Virtual machine plugin [4] is launched in a virtual commissioning software environment to generate the same movement as a realistic controller.

In addition to trajectory and process simulation, energy consumption models are developed providing the team with data of expected power consumption of industrial robots and their tools through the manufacturing process. The model discussed in this paper is based on a robot programmed in KUKA robot language that further extends the possibilities of robot trajectory processing to estimate the lifetime of robot semiconductor power modules depending on the intensity of movement program.

The paper investigates the impact of the realistic industrial robot mission profile on junction temperature and lifetime estimation until failure. Robot axis drive inverter isolated gate bipolar transistor junction (IGBT) temperature is calculated from mission profile-specific data set available from the energy consumption model. The input of lifetime estimation model is IGBT junction temperature, where junction temperature swings accelerate packaging degradation due to thermal expansion coefficient mismatch between adjacent materials.

\section{SIMULATION STUDY}

Simulation of energy consumption of industrial robots is a valuable tool for manufacturing site planning, as it is a tool for operation scheduling between multiple robots and trajectory planning for cost-effective production. Lifetime of the developed program is predicted 7 years of production, which is a common cycle in the automotive manufacturing industry; therefore, even minor efficiency improvements provide cost saving through the operating period.

There is a relationship between energy efficiency and reliability, as more efficient power consumption profile is less demanding for electronics of the robot power circuit. In addition, data from the model can provide other possibilities for reliability engineers considering the long-term performance of the system.

The novelty of the research is the calculation of lifetime consumption for power electronics modules of industrial robot inverter, depending on the created robot program and trajectory. Electrical data are known from the mechatronic model of robot, and trajectory is generated by a realistic controller simulation module, degradation of components as well as maintenance intervals can be considered.

Power consumption varies depending on the combined weight of tool and robot application type. It is assumed that degradation of components varies as well, due to the 
increased thermal loading on power electronics components, accelerating wear-out of solder joints and bond-wires. More agile application programs (handling, clinching, spot-welding) move or align parts quickly, while slow programs are limited by process quality such as adhesive bonding or painting. Accelerating to higher velocity requires creating larger amplitude power consumption peaks compared to lower velocity, and generates higher power peaks during deceleration as well. Increased kinetic energy provides larger recuperated energy during regenerative braking of robot axis motors.

Sample of KUKA KR220 6-DOF industrial manipulator welding program was generated with the realistic controller simulation module and simulated in kinematic and mechatronic model with different tool mass and analysed for the purpose of the research. Further simulation of handling, clinching and adhesive bonding (gluing) robot programs was conducted to review effects of various mission profiles on inverter semiconductor switch junction temperature.

Differences in simulated combined power consumption of robot motors during the same program with tool mass of $0 \mathrm{~kg}$ and $180 \mathrm{~kg}$ are shown in Fig. 1, resulting in a $5.9 \%$ difference of average power consumption. More detailed research of robot load weight effect on robot power consumption is available in [4].

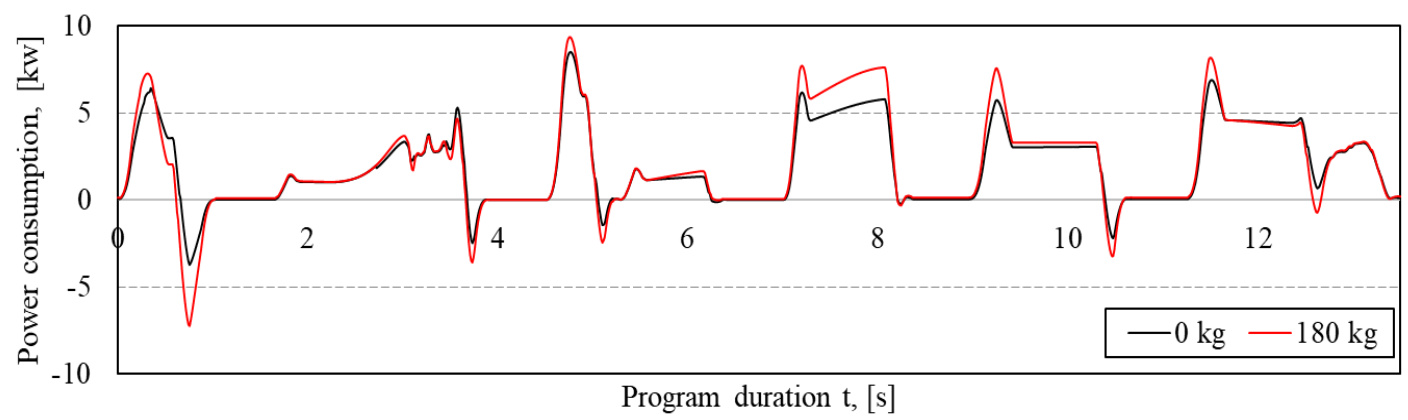

Fig. 1. Changing load weight effect on combined power consumption of industrial robot motors during sample welding program.

Mission profile translation from robot code to junction temperature of IGBT is required in order to estimate the lifetime of the power module. The model offers translation from movement path to electrical energy consumed or generated values during the robot movement profile. System performance calculations are supported by a mathematical model, being able to transfer data to and from virtual commissioning software through an application programming interface. In addition to the translation mechatronic model flow, calculation of power losses in inverter and IGBT and calculation of IGBT junction temperature and temperature change are performed as shown in Fig. 2.

The trajectory in the applied model is generated by KUKA specific realistic controller simulation module. The output of trajectory calculation is a file with axis rotation values in degrees. The next step of calculations and further transformation to electrical power losses within the virtual model of robot mechatronic hardware is supported by freeware Robotics Toolbox for MATLAB [5], [6]. Support of differential motion, 3D and 2D transformation functions from this toolbox is involved in data processing within the mechatronic robot model, providing an output of robot torque values. 

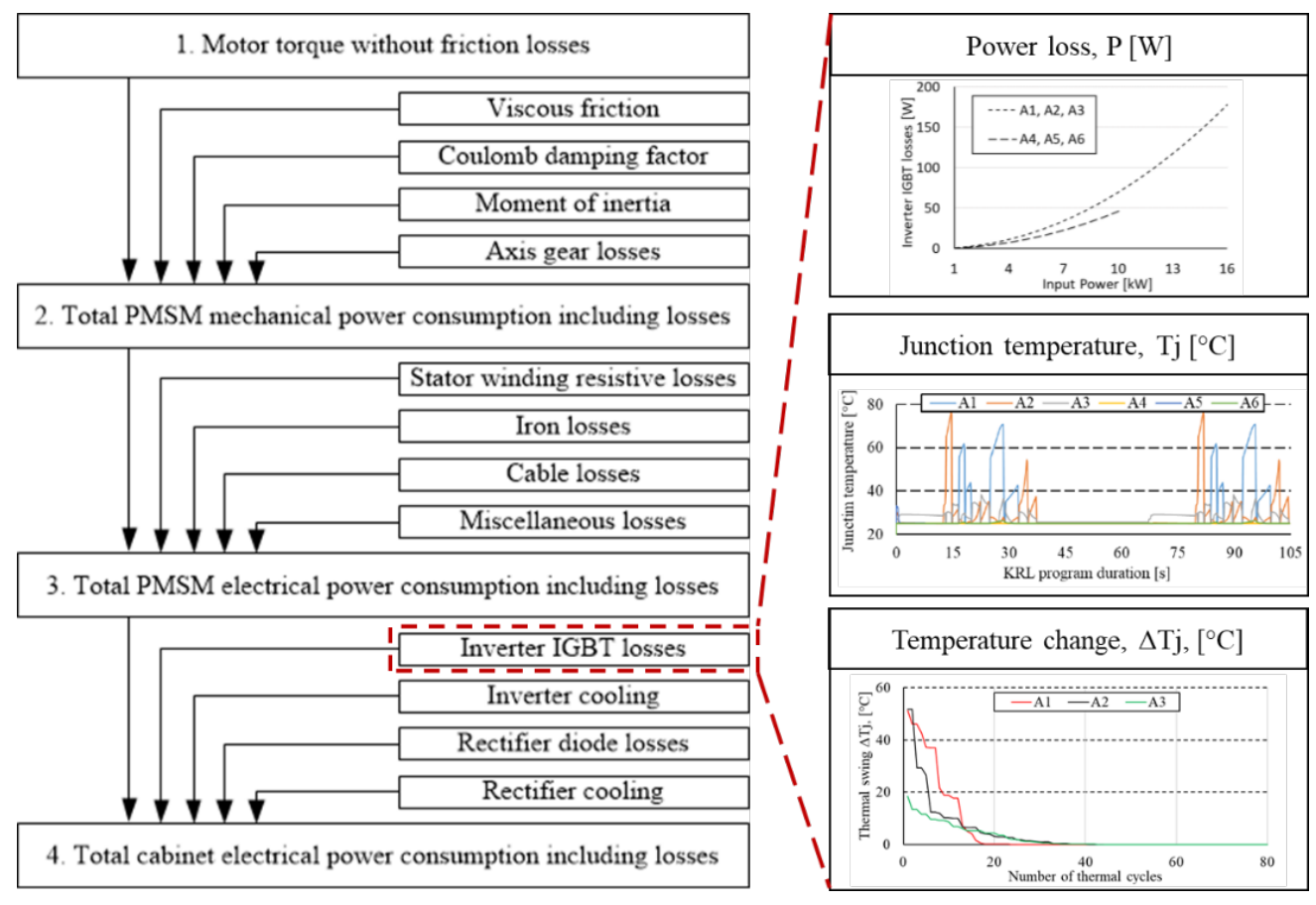

Fig. 2. Structure of electrical power consumption in a mechatronic model of the robotic system including mechanical and electrical losses, with capabilities to simulate the thermal profile of inverter semiconductor hardware.

Translated torque values of the simulated sample welding mission profile for each of robot axes through the program duration are shown in Fig. 3, being an input to further calculations in the model.
The torque of axes $1-3$ is higher, as they have to move more weight through movement, while axes 4-6 have to move significantly less weight; therefore, less torque is required.
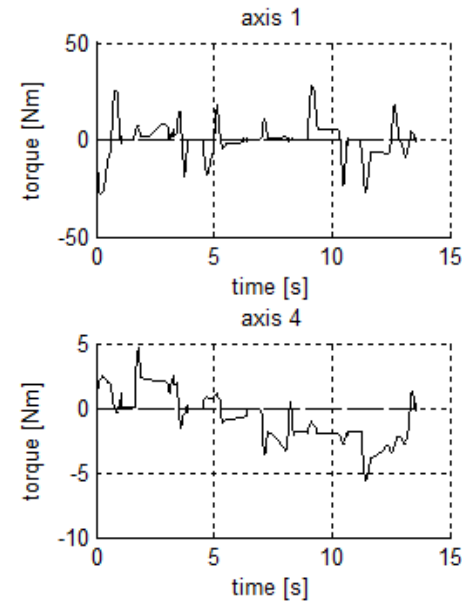
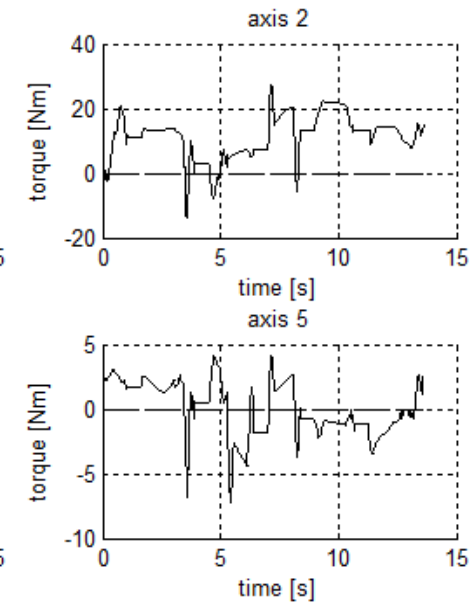
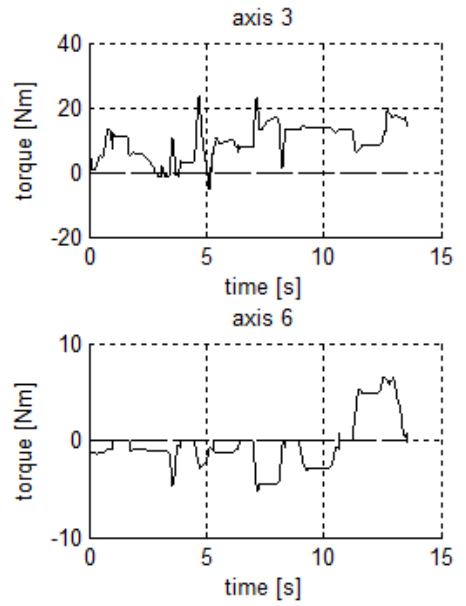

Fig. 3. The plot of translated axis torque values of six degrees of freedom industrial robot program code completing welding operation. 
Graphics functions, kinetic and dynamic models are just some of the options provided by the toolbox. 3D visualization is integrated into the model presented in this paper to review the specifics of analysed movement and support path planning and optimization research (see Fig. 4-a).

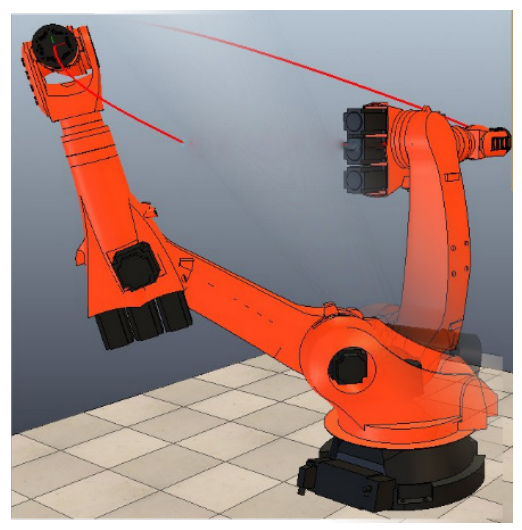

(a)

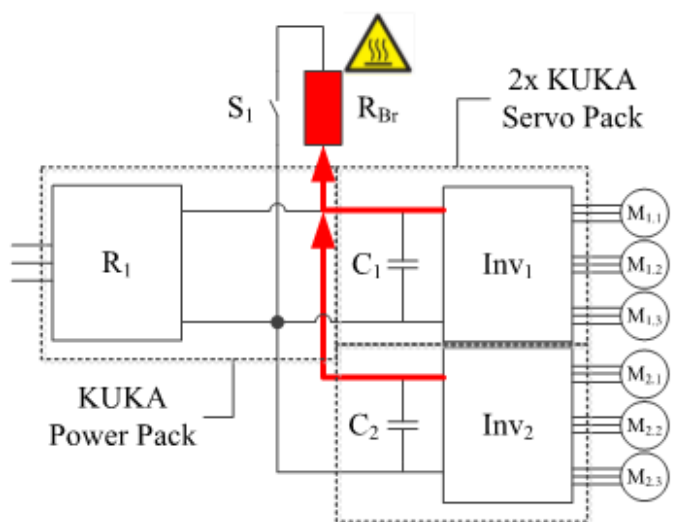

(b)

Fig. 4. Sample visualization of V-REP of robot program generated by the realistic controller simulation module with an imported 3D model of the manipulator (a). Typical layout of industrial robot system with single supply during regenerative braking dissipating energy in brake chopper (b).

Torque translation of robot movement axis without any mechanical losses is an input to a robot mechanical model, where additional losses such as friction, inertia, gear losses are considered and calculated [7]. Multiple robot models are supported, with their mass data available for robot links.

Tool weight and mass center are considered in simulation, affecting the instantaneous torque values of robot motors, since increased weight requires more electrical energy to accelerate to the same velocity, and generates more electrical energy during deceleration.

Mechanical torque with losses from robot drive is supplied as an input data to an electrical model of the selected industrial robot. Stator resistive losses, iron and cable losses of permanent magnet synchronous motors are considered at this stage of calculations.

After electrical losses of motors are added, all of the required input data to simulate electric cabinet (see Fig. 4-b) of the industrial robot are available. Cabinet simulation includes motor current, DC bus voltage, current energy stored in the capacitance of DC bus, brake chopper status and losses, as well as inverter and rectifier power losses.

As shown in Fig. 5, combined motor current consumption from DC bus peaks during acceleration, and is zero during deceleration, since no current is consumed when decelerating. The robot is keeping the angular position of its axes during six spot welding operations by holding motors in a fixed position for 0.6 seconds. Depending on the gravity force at each location, more or less current will be consumed during standstill.

Simulated electric cabinet of an industrial robot is a rectifier-inverter permanent magnet synchronous motor drive system with DC link, supported by external capacitance for energy storage and brake chopper for overvoltage protection. Voltage is recti- 
fied by KUKA Power Pack (rectifier unit) and inverted by KUKA Servo Pack (invert- ers), which return rectified voltage to DC link during regenerative braking.

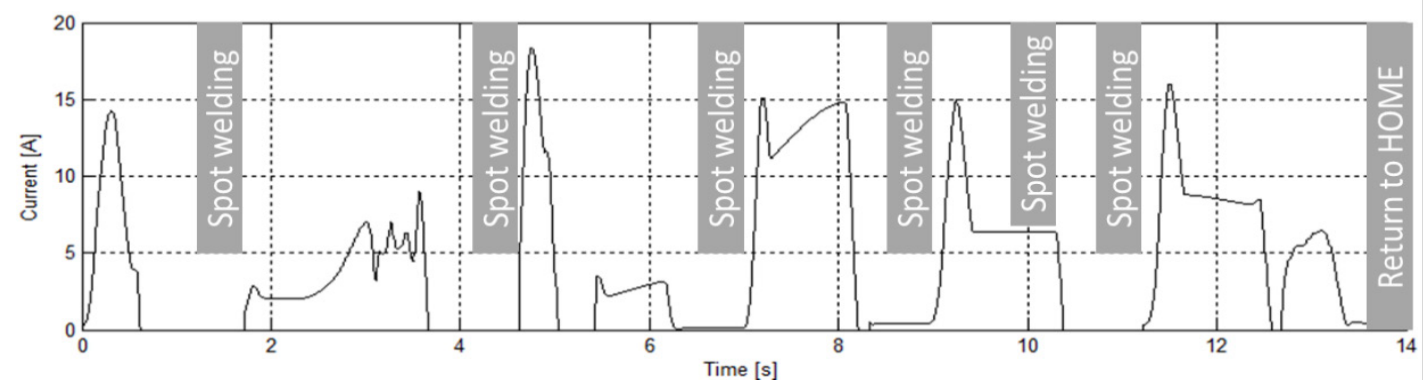

Fig. 5. Current in DC bus of the simulated system during sample welding operation with six scheduled spot-welding operations.

Each motor of the robot has its own inverter to control its operation, as shown in the principal power supply layout of KUKA industrial robot in Fig. 6. Six inverters are grouped in two KUKA Servo Pack units by the rated current. Axes 1-3 are supplied by inverters with the rated current of $40 \mathrm{~A}$, while the rated current of inverters that sup- ply axes $4-6$ is 20 A. This separation in groups is done since the load on the first three axes is significantly higher, as they are supporting the weight of the robot, tool and load. Axes 4, 5 and 6 control the approach angle of the tool and could be considered for fine-tuning of the movement.

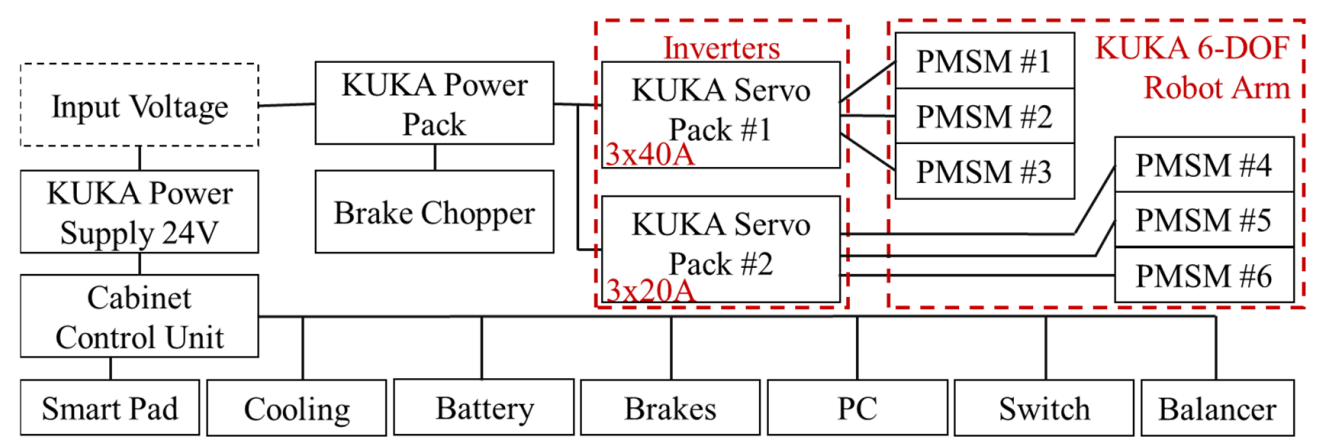

Fig. 6. Power supply circuit of KUKA industrial robot, including 2 KUKA Servo Pack modules to support the drive of robot axes.

For junction temperature estimation, the electrical losses of motors and input voltage of the DC bus change in time during robot movement are considered a mission profile. It contains data of current consumption for each of 6 degrees of freedom robot axis electric motors, as the motor current is supplied directly through semiconductor power modules of the inverter.

While mission profiles have the same constraints to maximal current consumption limited by hardware, different industrial robot applications will result in changing acceleration or deceleration slopes, duration, and other key parameters. In the presented model, the mission profile consists of six robot axis motor current consumption data in millisecond steps, through robot program duration. See sample motor current profile of each robot axis in Fig. 7-a. 


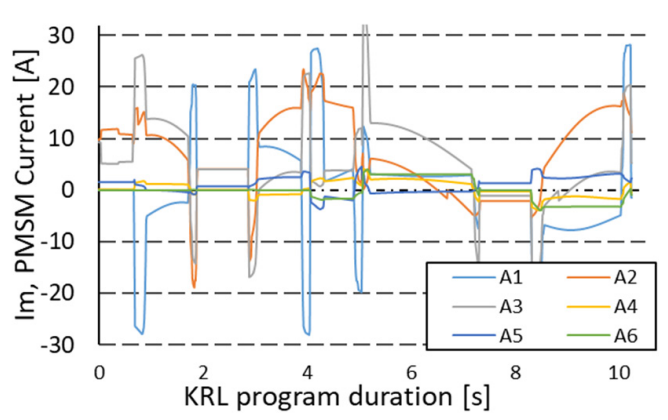

(a)

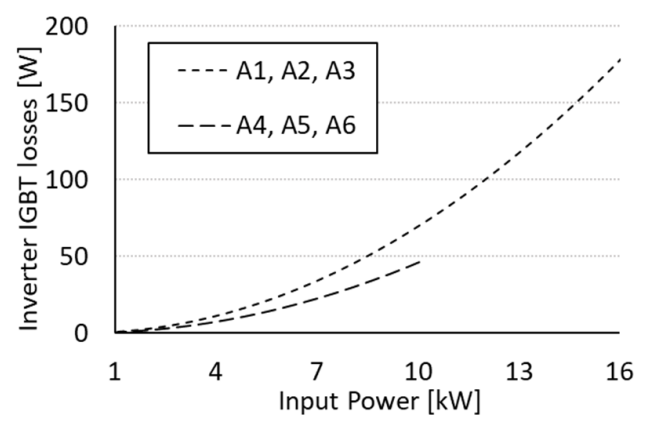

(b)

Fig. 7. The current of robot motor supplied through inverters of each robot axis (a). Inverter IGBT losses as a function of input power (b).

The current model evaluates inverter performance data to determine and estimate the lifetime of electronics hardware. Isolated gate bipolar transistor power losses are inverter power level dependent - higher power consumption leads to higher losses at semiconductor power modules. IGBT losses relationship to input power is illustrated in Fig. 7-b. Switching and resistive losses are estimated from the motor current of each axis considering the defined efficiency values, as shown in Eq. (1). In this model, anti-parallel diode efficiency is not separated from the power module. Constant KUKA Servo Pack operating losses not related to isolated gate bipolar transistors are included in the inverter power loss calculation model as well.

$$
\sum_{\mathrm{i}=0}^{\mathrm{t}} \mathrm{P}_{\text {cabinet }}(i)=\sum_{\mathrm{i}=0}^{\mathrm{t}}\left(\mathrm{P}_{\mathrm{PMSM}}(i)+\mathrm{P}_{\operatorname{inv}_{\mathrm{N}}}\left(\eta_{\operatorname{inv}_{\mathrm{KSP}}}\left(\frac{\mathrm{I}_{\mathrm{m}}(i)}{\mathrm{I}_{\mathrm{inv}_{\mathrm{N}}}}\right)+\eta_{\operatorname{inv}_{\mathrm{IGBT}}}\left(\frac{\mathrm{I}_{\mathrm{m}}(i)}{\mathrm{I}_{\operatorname{inv}_{\mathrm{N}}}}\right)^{2}\right)\right),
$$

where

$\mathrm{P}_{\text {cabinet }}$ - power consumption for each axis after addition of inverter losses (in $\mathrm{W}$ );

$\mathrm{P}_{\mathrm{PMSM}}-$ power consumption for permanent magnet synchronous motors of the robot for each axis (in W);

$I_{m}-$ motor current supplied through an inverter for each axis (in A);

$\mathrm{P}_{\mathrm{inv}_{\mathrm{N}}}$ - rated power consumption of KSP for each of 6 axes (in W);

$\mathrm{I}_{\mathrm{inv}_{\mathrm{N}}}$ - rated current of KSP (in A);

$\eta_{\text {inv } v_{\text {KSP }}}$ - efficiency loss of KSP inverter not related to IGBT per inverter unit;

$\eta_{\text {inv IGBT }_{\text {IGP }}}$ - efficiency loss of KSP inverter related to IGBT per inverter unit;

$\mathrm{t}-\mathrm{KRL}$ program duration (in $\mathrm{ms}$ ).

Further transformation of mission profile data is achieved by translation of instantaneous IGBT module electrical power losses to junction temperature, through the electro-thermal model of the semiconductor power module. To supply a motor of one robot axis, six modules are required and are considered equal regarding the distribu- tion of power losses and other parameters through this model. Rated current and voltage values of industrial robot power modules can reach 75 A, 600 V. Material package type will affect the model outcome, as it must be able to withstand high junction temperature and dissipate high power in losses. 
In the electro-thermal model, forced airflow from cabinet fan stabilizes ambient and heatsink temperatures. Total power losses at the IGBT module and anti-parallel diode are considered and included in IGBT/ diode junction temperature calculation as shown in Eq. (2). It includes values of various thermal impedances of the module from junction to ambient environment.

$T_{j}(t)=P(t) \cdot Z_{t h_{j-c}}+P(t) \cdot Z_{t h_{c-h}}+P(t) \cdot Z_{t h_{h-a}}+T_{a}(t)$,

where

$\mathrm{T}_{\mathrm{j}}$ - junction temperature of IGBT/diode of robot axis drive inverter (in ${ }^{\circ} \mathrm{C}$ );

$\mathrm{T}_{\mathrm{a}}$ - the ambient temperature of power module in KUKA Servo Pack (in ${ }^{\circ} \mathrm{C}$ );

$\mathrm{P}$ - combined power loss of IGBT/diode module (in W);

$Z_{t h j-c}$ - thermal impedance of power module from junction to the case (in ${ }^{\circ} \mathrm{C} / \mathrm{W}$ );

$Z_{t h_{c-h}}$ - thermal impedance of power module from case to heatsink (in ${ }^{\circ} \mathrm{C} / \mathrm{W}$ );

$Z_{t h_{h-a}}$ - thermal impedance from the heatsink to ambient environment (in ${ }^{\circ} \mathrm{C} / \mathrm{W}$ );

$\mathrm{t}-\mathrm{KRL}$ program duration (in $\mathrm{ms}$ ).

Parameters for simulation are obtained from technical datasheet. If the thermal impedance value of anti-parallel diode is available in the datasheet, it allows improving the accuracy of the model. Degradation of IGBT can be considered in the thermal model to improve accuracy as well [8]. Heatsink time delay is not considered in the current translation to junction temperature.

Wear-out of IGBT can be estimated from junction temperature data. Bond-wire damage and die-attach solder fatigue are common failure modes [9]-[11] accelerated by thermal cycling [8] in the field life or during accelerated testing, as they are caused by thermal expansion coefficient differences in package materials, leading from micro-cracks to eventual failure. Dieattach solder joint and bond-wire damage are linked, as degradation of a die-attach joint, lead to failure of bond-wire [12], [13].

\section{MISSION PROFILE AND JUNCTION TEMPERATURE}

Analysis of simulation results confirms a relationship between mission profile power consumption and robot motor inverter IGBT junction temperature. Two scenarios were reviewed during the research presented in this paper - changing tool mass and robot application type.

Junction temperature was compared simulating the same welding program mission profile and modifying tool mass. It was expected that heavier load will increase the junction temperature of IGBT modules. As shown in Fig. 8, the suggestion was confirmed and operating the same profile with heavier tool increased junction temperature. Axes 1-3 revealed a more significant increase in junction temperature as these axes are affected the most by the increase of tool weight, while robot axes 4-6 are less affected by the increased weight, due to the role of approach angle positioning and being less affected by the pull of gravity. 

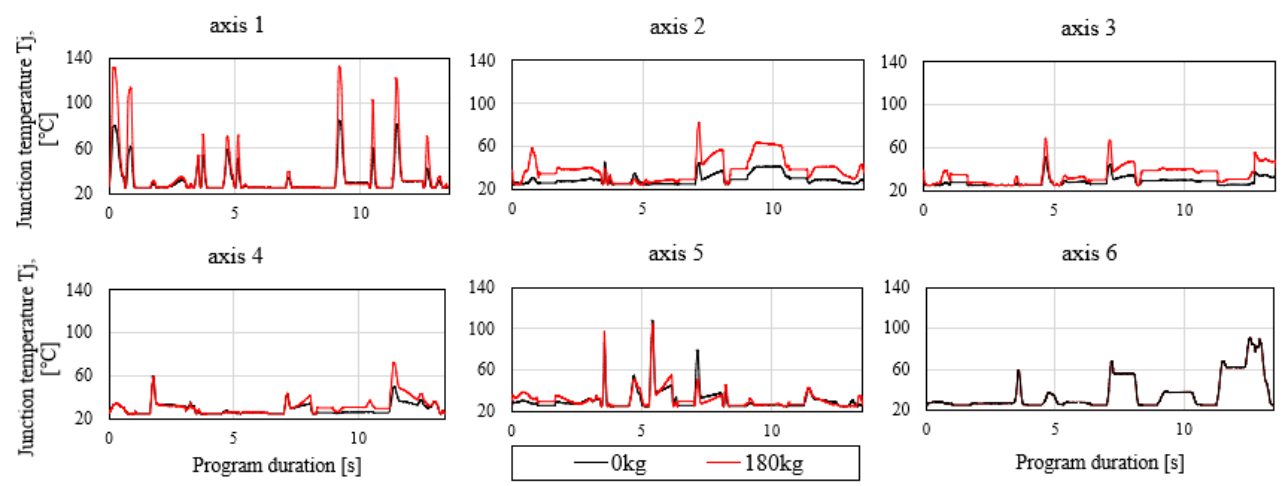

Fig. 8. Simulated IGBT junction temperature comparison of industrial robot with various weight tools performing spot-welding program.

IGBT junction temperatures of multiple six degrees of freedom industrial robot programs were simulated and analysed, changing the type of robot program. The expectation of this research is to confirm that more agile robot programs with overall higher velocity and power consumption lead to increased junction temperatures in robot hardware. See Table 1 for more detailed data of simulated robot programs.

Table 1. Detailed Data of Simulated Various Application Robot Programs

\begin{tabular}{|l|c|c|c|c|}
\hline Program name & Duration $[\mathrm{s}]$ & Tool mass $[\mathrm{kg}]$ & Average power $[\mathrm{kW}]$ & Program description \\
\hline Handling & 10.25 & 125 & 3.70 & High velocity \\
\hline Clinching & 9.31 & 50 & 2.45 & High velocity, stop \& go \\
\hline Spot welding & 13.66 & 180 & 2.65 & High velocity, stop \& go \\
\hline $\begin{array}{l}\text { Adhesive } \\
\text { bonding }\end{array}$ & 11.10 & 50 & 2.12 & $\begin{array}{c}\text { High approach velocity; } \\
\text { low velocity, high } \\
\text { precision dispensing }\end{array}$ \\
\hline
\end{tabular}

Designed characteristics of handling program are to change location from home location to load pick-up area with the highest velocity, i.e., transport load to processing point, unload, and return to a home position. Access of loading area is easy and does not require a lot of positioning angle adjustment. Handing operation is agile, with high velocity, to avoid creating any production bottlenecks.

Simulated clinching operation is similar to handling program - agile and with high velocity when moving between programmed points. It has five scheduled stop and wait commands through the program to support the clinching operation of the robot tool. Access to operation spots is sophisticated and requires extensive positioning angle adjustment.

Spot welding is agile and with high velocity as well, since moving from one weld location to other is expected to be done as quickly as possible to increase production output quantity. It has 6 scheduled welding spots as mentioned earlier. The main difference between spot welding or clinching from handling operation is more acceleration from complete standstill due to multiple processing points.

Adhesive bonding robot profile is designed manufacturing process speedsensitive. The robot is approaching gluing location quickly, then moves the glue dispensing tool with process-safe velocity and returns to home location as soon as the glue application is complete. 
IGBT junction temperature reaches higher values for programs with higher robot velocity - handling, clinching, also spot welding, as shown in Fig. 9. Tempera-
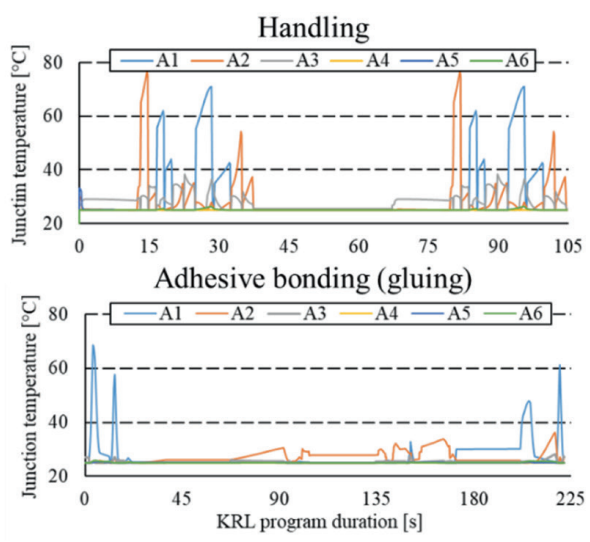

Fig. 9. The simulated IGBT junction temperature of each robot axis during sample robot programs in various applications - handling, clinching, adhesive bonding, welding.

To estimate degradation of IGBT modules of industrial robot inverter due to mission profile, calculation of thermal swing $\Delta T_{j}$ is required. Data from simulated robot programs are further translated, revealing the mission profile potential impact on the remaining lifetime of the semiconductor switch.

As shown in Fig. 10, the gluing operation has the least number of significant junction thermal cycles and amplitudes for robot axes are smaller, since just approach ture peaks during acceleration of axis motor remain steady during steady operating speed and cool down when the axis motor is stopped.
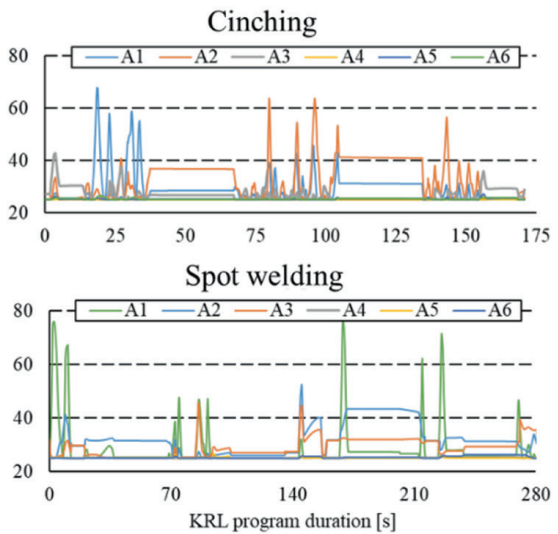
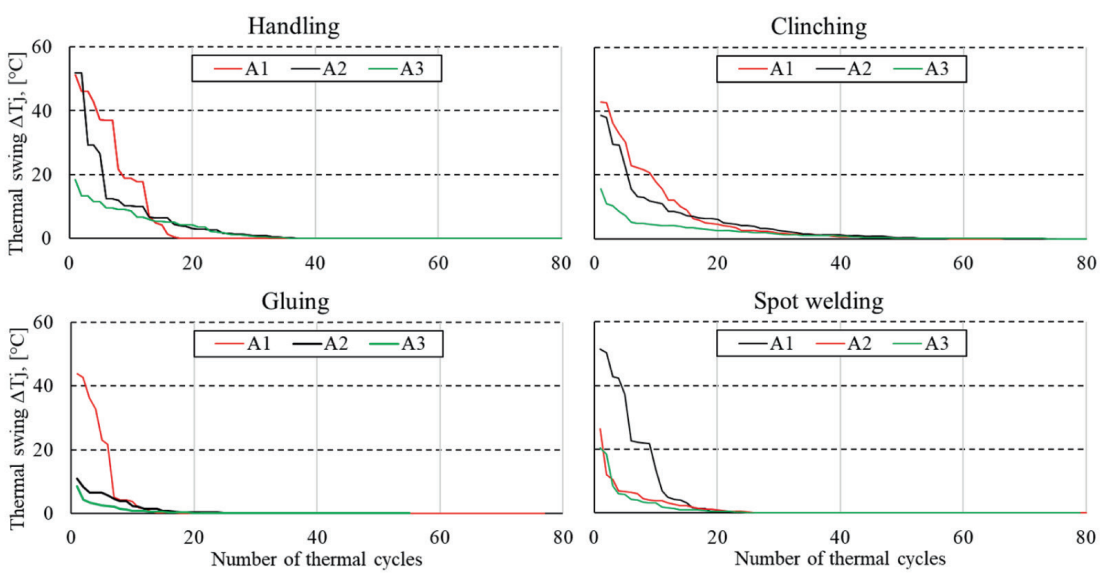

Fig. 10. Number of thermal swing amplitudes and cycles during simulated programs of sample robot applications. 
The novel capability of IGBT junction temperature, thermal swing quantity and amplitude simulation has been added to the mechatronic system model of six degrees of freedom industrial robot. Introduced calculations are intended to be used for IGBT lifetime reduction evaluation regarding various mission profiles translated from robot program code.

While verification of current junction temperature results with field data is not completed, the current model already provides an opportunity to quickly test various remaining lifetime improvement concepts and highlight impact factors such as tool mass, stop-to-standstill cycles, program velocity, average current consumption, and others. Predictive maintenance schedule on-site can be adjusted depending on the robot program profile, as not all hardware has degraded equally.

Development of lifetime consumption models and lifetime distribution based on the developed mission profile translation is scheduled as future work to continue this research.

\section{ACKNOWLEDGEMENTS}

The research has been supported by the Ministry of Economics of the Republic of
Latvia, project RTUAER, project No. VPPEM-AER-2018/3-0004.

\section{REFERENCES}

1. Dassault Systems. (n.d.) Assembly Robot Programmer. Available at https://www.3ds. com/products-services/delmia/disciplines/ industrial-engineering/

2. ABB, RobotStudio®. (n.d.). Available at https://new.abb.com/products/robotics/ robotstudio

3. KUKA AG. (n.d.). KUKA.Sim. Available at https://www.kuka.com/en-gb/products/ robotics-systems/software/simulationplanning-optimization/kuka_sim

4. Bormanis, O. (2015). Development of energy consumption model for virtual commissioning software. In 56th International Scientific Conference on Power and Electrical Engineering of Riga Technical University (RTUCON), (pp. 1-4), 14 October 2015, Riga, Latvia.
5. Corke, P. (n.d.). Robotics Toolbox for MATLAB. Available at https://petercorke. com/toolboxes/robotics-toolbox/

6. Corke, P. (n.d.). Robotics Toolbox 10 for MATLAB. Available at https://petercorke. com/download/27/rtb/1050/rtb-manual.pdf

7. Hansen, C., Öltjen, J., Meike, D., \& Ortmaier, T. (2012). Enhanced approach for energy-efficient trajectory generation of industrial robots. In 2012 IEEE International Conference on Automation Science and Engineering (CASE), (pp. 1 7), 20-24 August 2012, Seoul, Korea.

8. Sintamarean, C., Blaabjerg, F., Wang, H., \& Iannuzzo, F. (2015). Reliability Oriented Design Tool for the New Generation of Grid Connected PV Inverters. IEEE Trans. Power Electron., 30 (5), 2635-2644. 
9. Huang, H., \& Mawby, P. A. (2013). A Lifetime Estimation Technique for Voltage Source Inverters. IEEE Trans. Power Electron., 28, (8), 4113-4119.

10. Ciappa, M. (2002). Selected Failure Mechanisms of Modern Power Modules. Microelectron. Reliab., 42, pp. 653-667.

11. Bayerer, R., Hermann, T., Licht, T, Lutz, J., \& Feller, M. (2008). Model for power cycling lifetime of IGBT modules various factors influencing lifetime. In Proc. 5th Int. Conf. Integr. Power Electron. Syst., (pp. 1-6), 6-8 March 2008, Nuremberg, Germany.

12. Scheuermann, U., \& Hecht, U. (2002). Power cycling lifetime of advanced power modules for different temperature swings. In Proc. PCIM Nuremberg, (pp. 59-64), June 2002, Nuremberg, Germany.

13. Lee, W. W., Nguyen, L. T., \& Selvaduray, G. S. (2000). Solder Joint Fatigue Models: Review and Applicability to Chip Scale Packages. Microelectron. Reliab., 40, 231244. 